\begin{tabular}{|c|l|}
\hline Title & $\begin{array}{l}\text { Interface Shear Transfer of Diagonally Arranged Reinforcing Bars } \\
\text { under Repeated Loading }\end{array}$ \\
\hline Author & $\begin{array}{l}\text { Takahashi, Kosuke / Kitoh, Hiroaki / Tsunokake, Hisao / Ohuchi, } \\
\text { Hajime }\end{array}$ \\
\hline Citation & $\begin{array}{l}\text { Memoirs of the Faculty of Engineering Osaka City University. } \\
\text { Vol.49, pp.67-74. }\end{array}$ \\
\hline Issue Date & $2008-12$ \\
\hline ISSN & $0078-6659$ \\
\hline Type & Departmental Bulletin Paper \\
\hline Textversion & Publisher \\
\hline Publisher & Graduate school of Engineering, Osaka City University \\
\hline Description & \\
\hline
\end{tabular}

Placed on: Osaka City University Repository 


\title{
Interface Shear Transfer of Diagonally Arranged Reinforcing Bars under Repeated Loading
}

\author{
Kosuke TAKAHASHI*, Hiroaki $\mathrm{KITOH}^{* *}$, Hisao TSUNOKAKE*** and Hajime OHUCHI****
}

(Received September 30, 2008)

\section{Synopsis}

We focus on dowel action, which is one of the shear transfer mechanisms on the crack interfaces of $\mathrm{R} / \mathrm{C}$ members. Therefore, we carried out experiments under repeated loading with the push-off type test specimens. Our purposes are to examine shear transfer mechanism of rebar diagonally arranged on the crack interface and also hysteretic characteristics of shear force vs. displacement. The following conclusions can be drawn: First, shear transfer due to the dowel action could be explained by a cantilever model based upon linear moment distribution assumption; Second, transferred shear force comprised of $15 \%$ for dowel action and $85 \%$ for axial force action in case of rebar arranged diagonally; Last, less energy absorption could be expected because of dominate crack opening in concrete and, in contrast, rebar remained in elastic.

KEY WORDS: shear transfer, dowel action, repeated loading

\section{Introduction}

It is important to investigate the shear transfer mechanism which includes aggregate interlock and dowel action on the RC crack interface. This study focuses on only the dowel action. Many studies have been carried out on the dowel action due to a reinforcing steel bar, called as rebar hereafter, arranged perpendicularly onto the crack surface. However, in general crack surface is not always perpendicular to the axial direction of the rebar, so that the rebar can work as not only dowel but also axial action. Nevertheless, less study has been conducted on the shear transfer of the rebar diagonally arranged on the crack interface, in particular, under repeated loading. Thus, we carried out experiments under repeated loading with five push-off type test specimens as shown in Photo.1.

The purposes of our study are to investigate the shear transfer mechanism of rebar diagonally arranged on interface, and also hysteretic relation between applied shear force and relative displacement along the crack interface.

\footnotetext{
* $\quad$ Student, Master Course of Department of Civil Engineering

** Associate Professor, Department of Civil Engineering

*** Research Associate, Department of Civil Engineering

**** Professor, Department of Civil Engineering
} 


\section{Experiments}

\subsection{Test Specimens}

Typical specimens we used are shown in Photo.1. A specimen was composed of L-shaped two concrete blocks in asymmetric layout and a couple of the rebar connecting the blocks. Bold broken black lines in the Photo.1, indicate the single layered rebar arrangement, which rebar was so-called D16 having nominal diameter and cross sectional area were $16 \mathrm{~mm}$ and $199 \mathrm{~mm}^{2}$, respectively. Furthermore, bold line segments also denote uni-axial strain gauge arrangements on the rebar. In each specimen, moreover, another action for shear transfer on the interface than action due to the rebar was removed by a thin acryl plate.

Two of the test parameters were an interface opening distance "e" and also a rebar arranged angle " $\alpha$ " to the interface as shown in Photo.1. As shown in Photo.1(b), the distance "e" in specimens group B was intended to draw a potential plastic behavior of the rebar. The plastic behavior to be expected is capable for the damping equipment. On the other hand, as shown in Photo.1(c), the angle " $\alpha$ " in specimens group $\mathrm{C}$ was implemented to identify shear transfer mechanism of rebar diagonally arranged on interface.

The mechanical properties of the material used herein are also listed in Table 2.

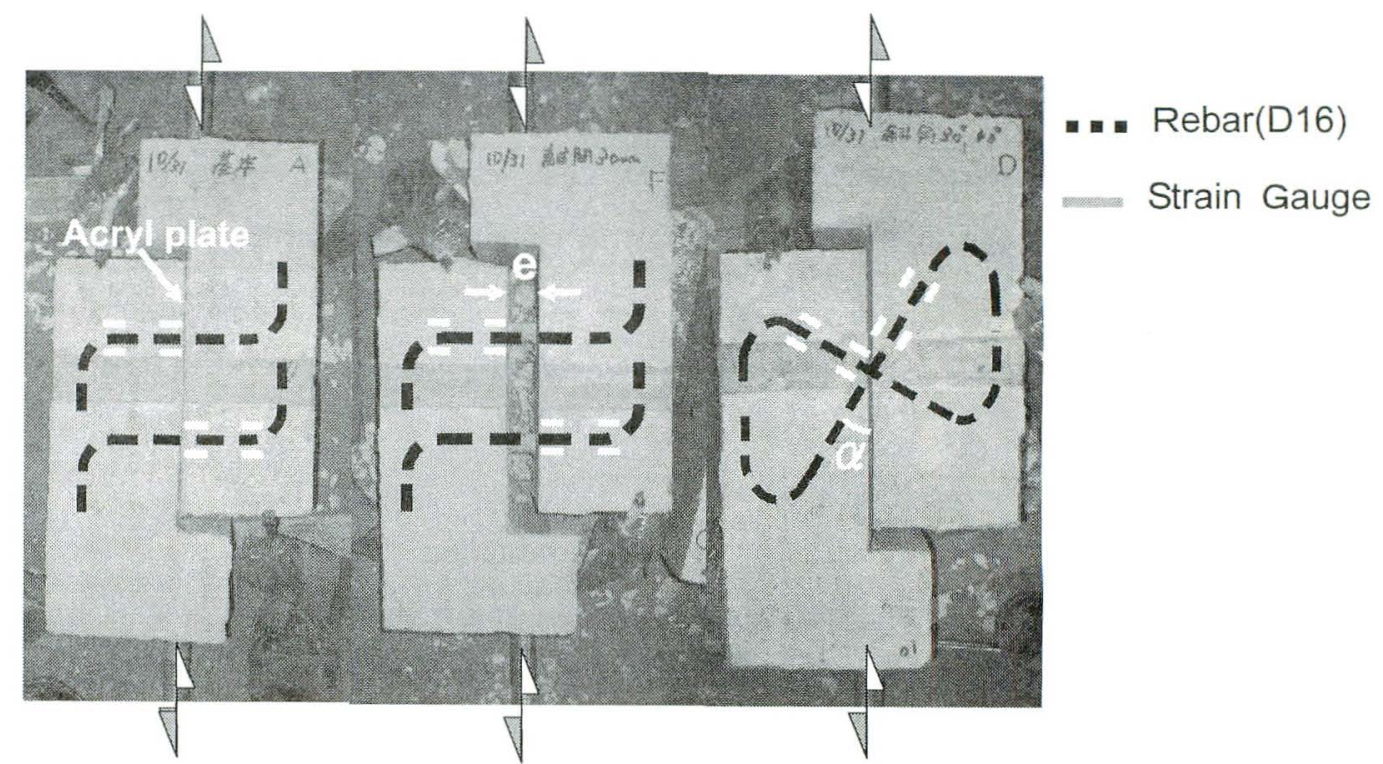

(a)

(b)

(c)

Photo.1 Specimens

Table.1 Test Parameters

\begin{tabular}{ccccc}
\hline Group & Tag & $e$ & $\alpha$ & Photo.1 \\
\hline A & A-0-90 & 0 & $90^{\circ}$ & (a) \\
\hline \multirow{2}{*}{ B } & B-15-90 & $\mathbf{1 5 m m}$ & $90^{\circ}$ & (b) \\
\cline { 2 - 5 } & B-30-90 & $\mathbf{3 0 m m}$ & $90^{\circ}$ & (b) \\
\hline \multirow{2}{*}{ C } & C-0-45 & 0 & $\mathbf{4 5}^{\circ}$ & (c) \\
\cline { 2 - 5 } & C-0-30,60 & 0 & $\mathbf{3 0 , 6 0 ^ { \circ }}$ & (c) \\
\hline
\end{tabular}


Table.2 Material Properties

\begin{tabular}{c|c|c}
\hline Materials & Properties & Values \\
\hline \multirow{2}{*}{ Rebar } & Elastic Modulus & $183[\mathrm{GPa}]$ \\
\cline { 2 - 3 } & Yield Stress & $349[\mathrm{MPa}]$ \\
\hline \multirow{4}{*}{ Concrete } & Compressive Stress & $36.2[\mathrm{MPa}]$ \\
\cline { 2 - 3 } & Tensile Stress & $2.60[\mathrm{MPa}]$ \\
\cline { 2 - 3 } & Elastic Modulus & $29.0[\mathrm{GPa}]$ \\
\cline { 2 - 3 } & Poisson's Ratio & 0.21 \\
\hline
\end{tabular}

\subsection{Test Procedure}

An example of the test setup we used is shown in Photo.2. Screw cutting round bars embedded both on top and bottom surfaces of the specimen were to be connected to the testing machine.

Repeated loading tests were controlled based on an incremental displacement. Prescribed displacements were $0.5 \mathrm{~mm}, 1.0 \mathrm{~mm}$ and $1.5 \mathrm{~mm}$ with three cycles for each the displacement. Relative displacement along the interface was measured by a displacement gauge as shown in Photo.3, and also axial and bending strains of the rebar were observed by the couple of uni-axial strain gauges as shown in Photo.1.

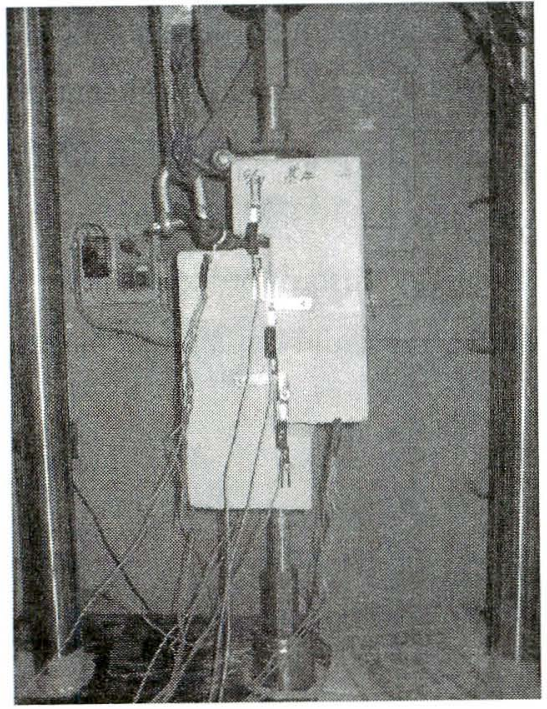

Photo.2 Installed Test Specimen

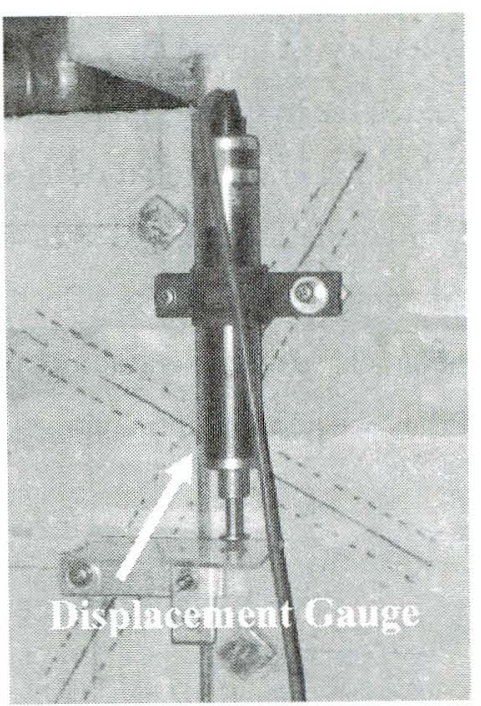

Photo.3 Displacement Gauge

\section{Test Results}

\subsection{Crack Pattern}

The crack pattern of A-0-90 is shown in Fig.1(a). Remarkable splitting cracks from the interface were observed both on the front and rear surfaces along the rebar arrangements. Similar crack patterns were, moreover, found in the specimens group B with distance "e" as shown in Fig.1(b). On the other hand, in the specimens group C with angle " $\alpha$ ", none of the splitting cracks could appear along the rebar arrangements as shown in Fig.1(c). These cracks significantly affected the shear transfer mechanism described hereafter. 


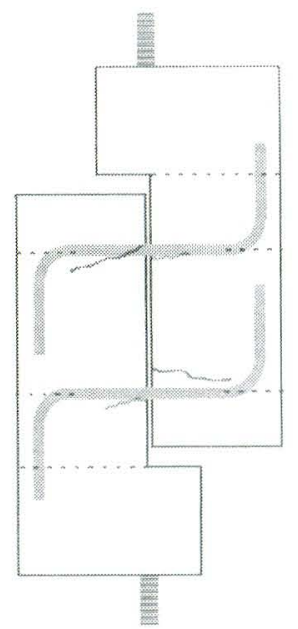

(a) $\mathrm{A}-0-90$

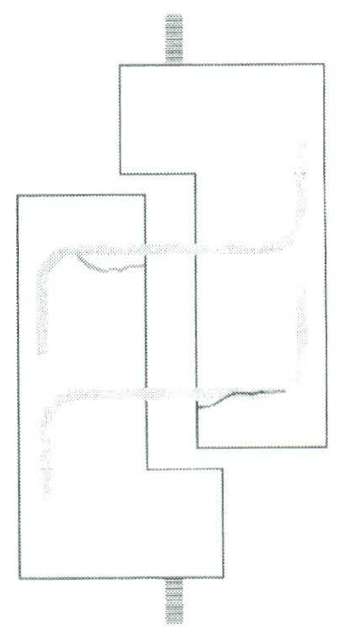

(b) $\mathrm{B}-30-90$

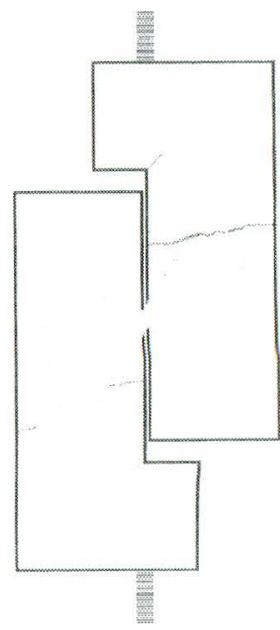

(c) $\mathrm{C}-0-30,60$

Fig.1 Crack Pattern

\subsection{Load Displacement Hysteretic Characteristics}

\subsubsection{Load-Displacement Relationships}

Figure 2 shows load-displacement relationships of all the specimens. In the figure, positive directions of vertical axes were defined that the shear force made the blocks in Photo.1 vertically apart from each other. The shear force loading in the positive direction is also called as tensile loading. In all the specimens, the asymmetry was observed in the hysteresis loop. This may be lead that concrete cover depth was insufficient in tensile loading, so that the splitting cracks could develop with obvious opening, while the cracks closed in compressive loading. Therefore, in tensile loading, the measured relative displacements inevitably included the crack mouth opening distance. In addition, a pinching effect was so pronounced, that energy absorption could be less than expected, because the crack development and opening was dominated, and the rebar did not show a plastic behavior up to the end of the repeated loading.
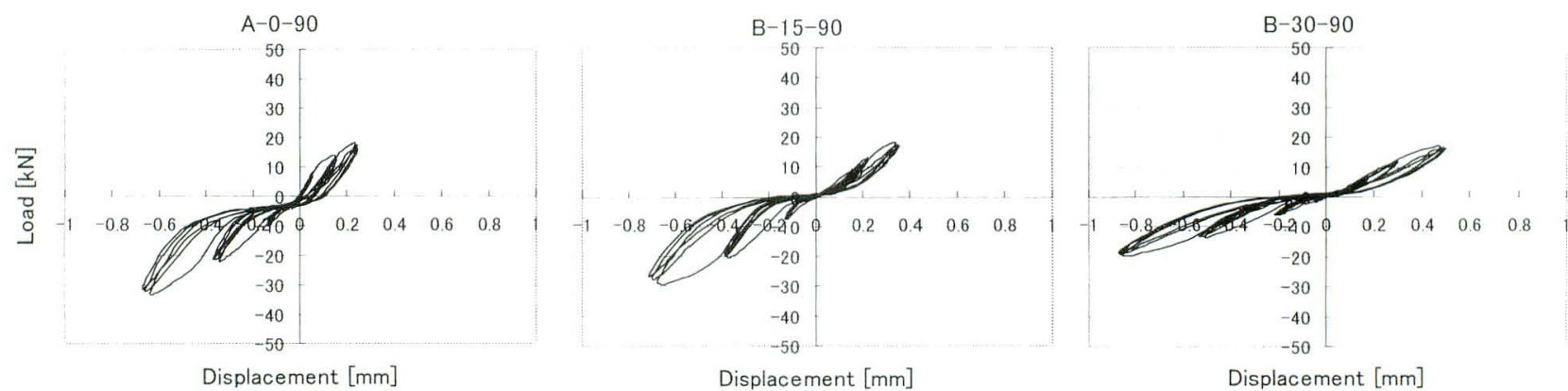

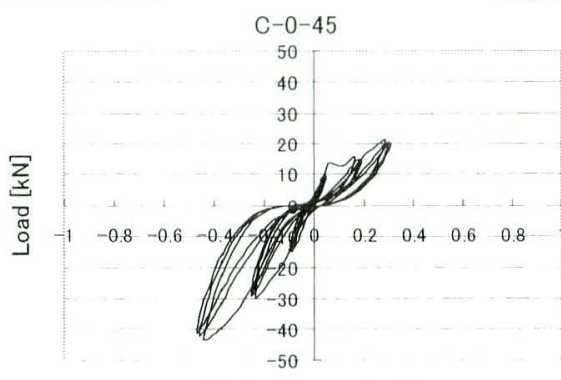

Displacement $[\mathrm{mm}]$

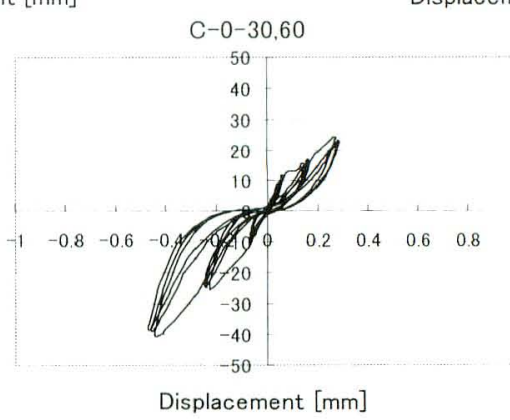

Fig.2 Load-Displacement Relationships 


\subsubsection{Shear Stiffness}

Shear stiffness due to the dowel action is defined herein as the slope of the line through points coordinate origin and maximum load of first cycle for each amplitude $(0.5,1.0,1.5 \mathrm{~mm})$. Figure 3 shows the stiffness for each specimen. Compared with A-0-90 and the specimens, the stiffness of Group B having the interface opening distance were inferior, because deformability of the rebar was improved by setting up the opening distance. Next, the stiffness of Group C with the rebar diagonally arranged were superior to that of A-0-90, because a resistance by axial force in the diagonal rebar was generated.

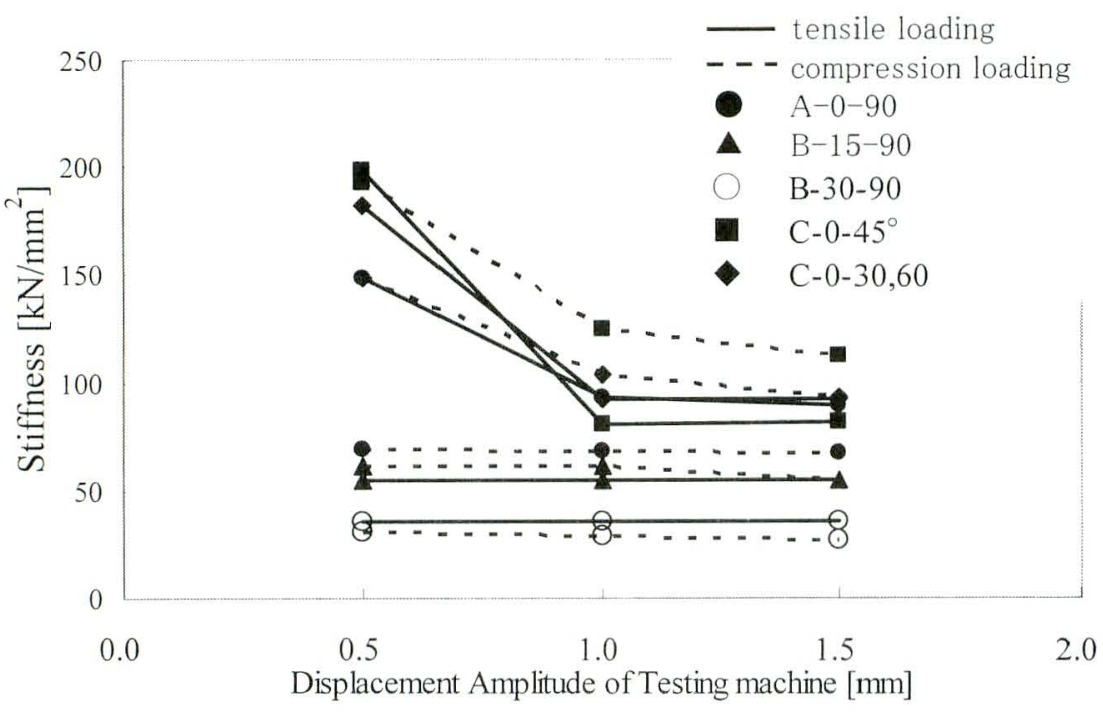

Fig.3 Stiffness-Displacement Amplitude Relationships

\subsubsection{Hysteretic Damping}

As shown in Fig.2, the obtained hysteresis loop area, as a useful index of hysteretic damping, was considerably small in all specimens. The envelope of these loops was regarded as a typical feature of shear-sensitive reinforced concrete structural elements. It was also recognized from the loops that less energy absorption was due to the dominate crack and elastic behavior of the rebar. The left part of Fig.4 shows equivalent damping factors: $h_{\mathrm{eq}}$ calculated by the manner illustrated in the right part of the figure"). The superior factor values were obtained in diagonally arranged rebar case, while the inferior values obtained in the group B with the opening distance of the interface.
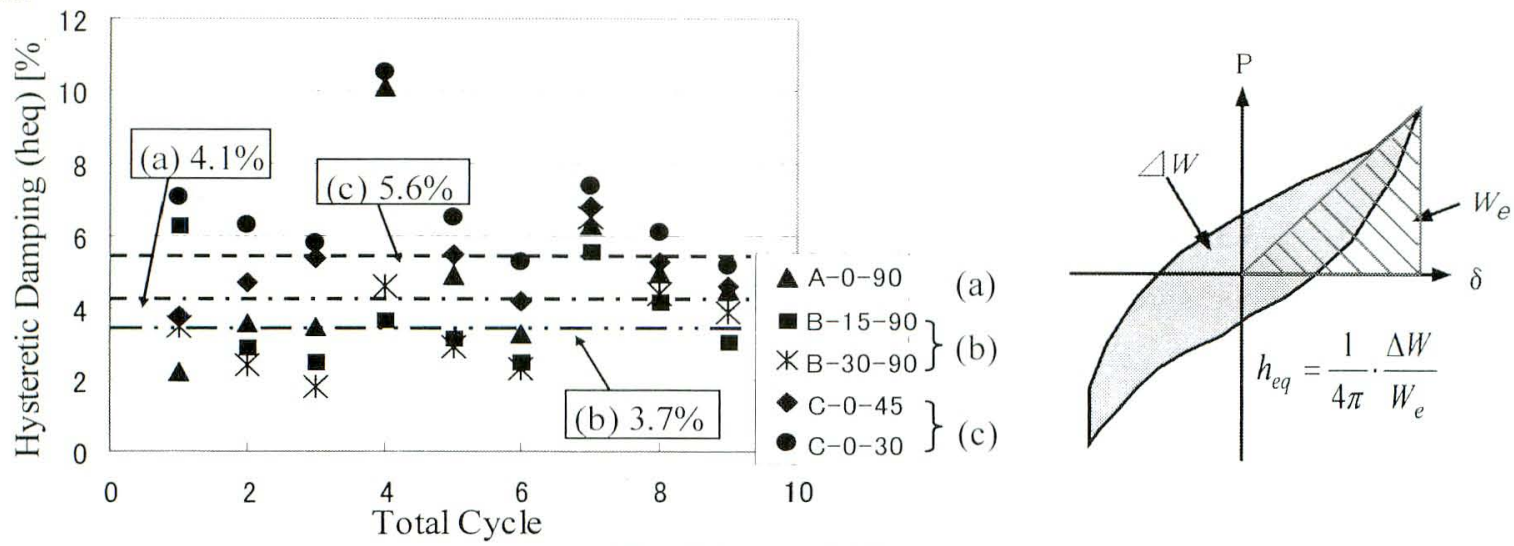

Fig.4 Hysteretic Damping 


\subsection{Shear Transfer Characteristics of Rebar}

\subsubsection{Dowel Action}

In the test specimen of A-0-90, the shear transfer due to the dowel action could be explained by a cantilever model with linear moment distribution assumption as shown in Fig.5. This assumption could be verified satisfactory as shown in Fig.6, where theoretical moment $M_{\text {thoo. }}$ calculated from Eq. (1) agreed with the obtained experimental moment at measured point $M_{\text {exp. }}$ which was calculated from flexural strain ( Eq. (2)).

The shear transfer due to the dowel action in the other specimens could also be explained by the same way.

$$
\begin{gathered}
M_{\text {theo. }}=P \sin \alpha \times x \\
M_{\text {exp. }}=\frac{2}{d_{b}} E_{s} I_{s} \varepsilon_{M}
\end{gathered}
$$

where $P$ is applied shear force; $x$ is distance from interface to the measure point; $d_{b}, E_{s}, I_{s}$ and $\varepsilon_{M}$ are diameter, elastic modulus, moment of inertia and flexural strain of the rebar.

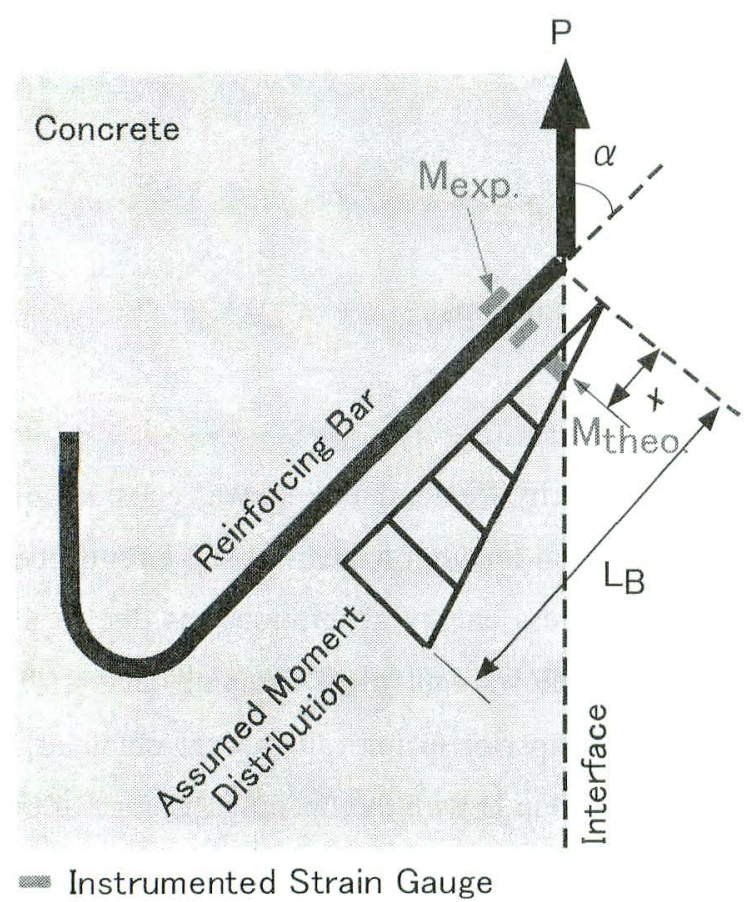

Fig.5 Cantilever Mechanism

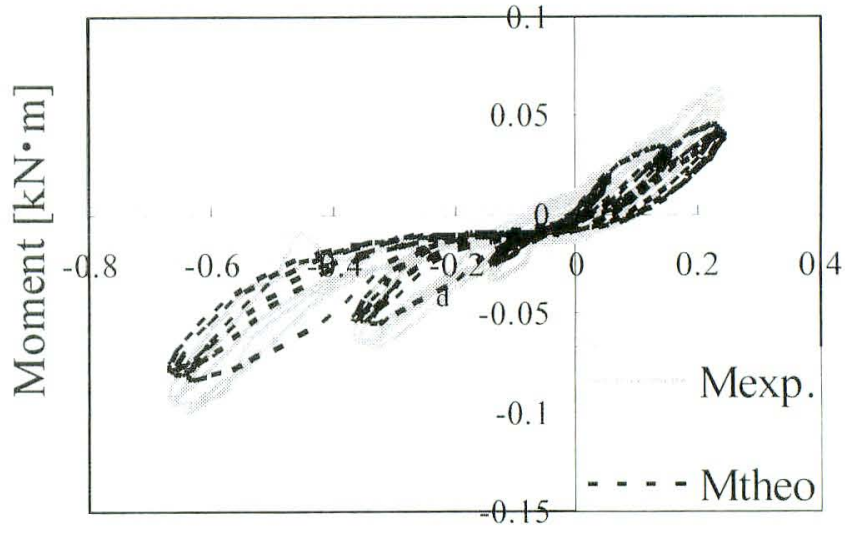

Displacement [mm]

Fig.6 Rebar Moment-Displacement Relationship (A-0-90)

\subsubsection{Shear Transfer Characteristics of Rebar Diagonally Arranges}

Figure 8 shows a good agreement of the hysteretic characteristics of C-0-45 between the monitored load and the calculated one from Eq. (3) (5) based on the measured strain on the rebar as shown in Fig.7. Moreover Fig.9 also shows a good agreement between monitored load P and measured shear force Q as shown in Fig.7. Therefore, in the specimen C-0-45, applied shear force was transferred as flexural force action and axial force action of rebar. In addition, the ratio of flexural force to axial force calculated from Eq. (6) was 15 to 85 as 
shown in Fig.10. At the same time, calculated for C-0-30,60 in the same way, the ratio was 30 to 70.

$$
\begin{gathered}
Q=Q_{M} \sin \alpha+Q_{N} \cos \alpha \\
Q_{M}=\frac{M_{\text {exp. }}}{x} \\
Q_{N}=\varepsilon_{N} E_{s} A_{s} \\
\frac{Q_{M}}{P} \text { and } \frac{Q_{N}}{P}
\end{gathered}
$$

where $Q_{M}$ is calculated as the measured flexural moment divided by distance from the interface, $Q_{N}$ is calculated by multiplying axial strain of rebar $\varepsilon_{N}$ by $E_{s}$ and $A_{s}$ (cross section of rebar).

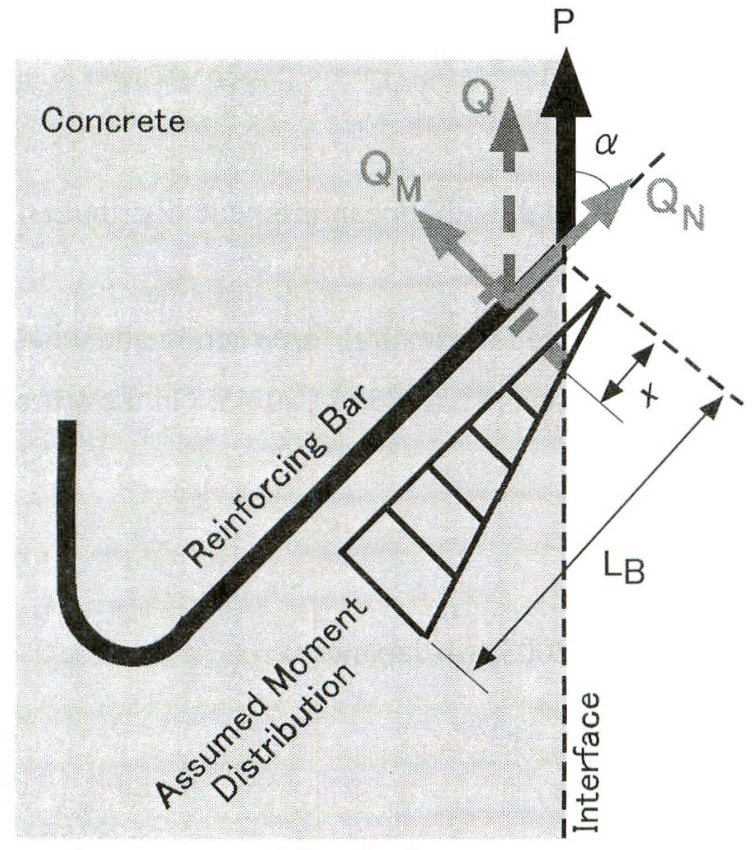

Instrumented Strain Gauge

Fig.7 Definition of Q

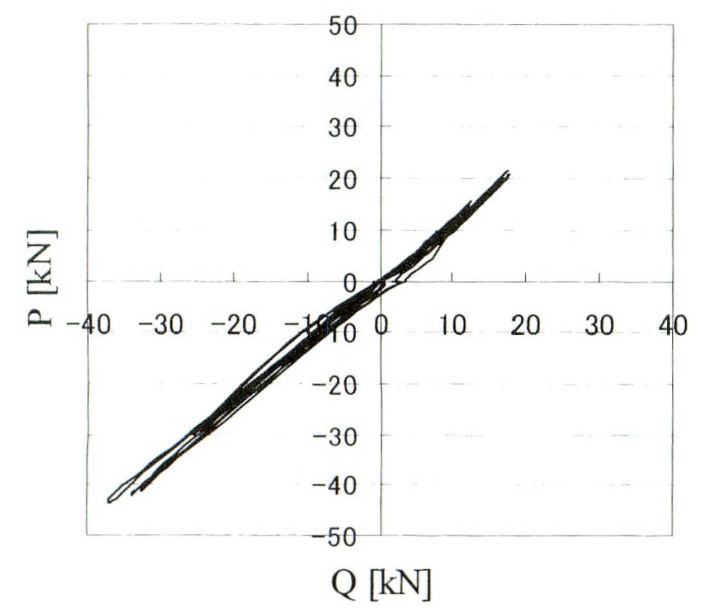

Fig.9 P-Q Relationship (C-0-45)

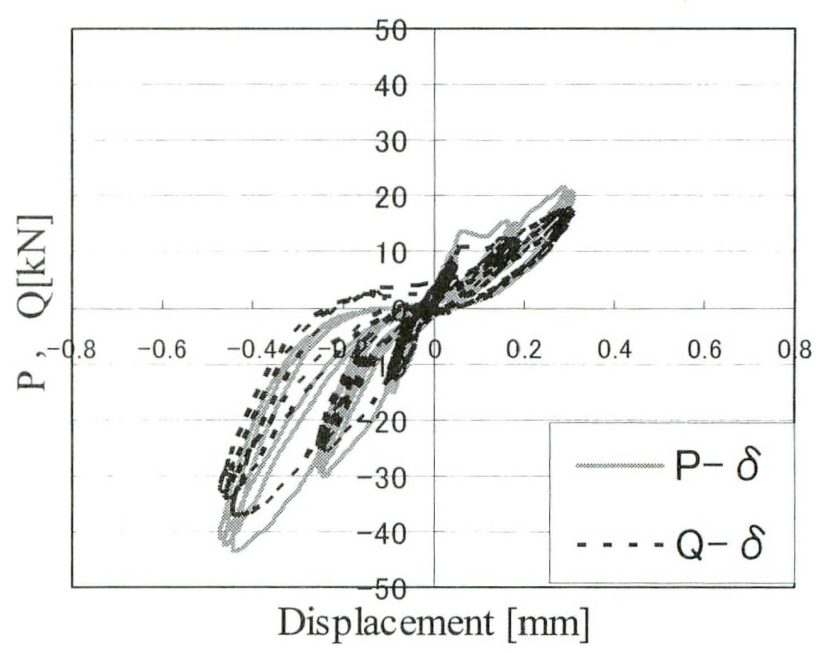

Fig.8 P, Q -Displacement Relationship (C-0-45)

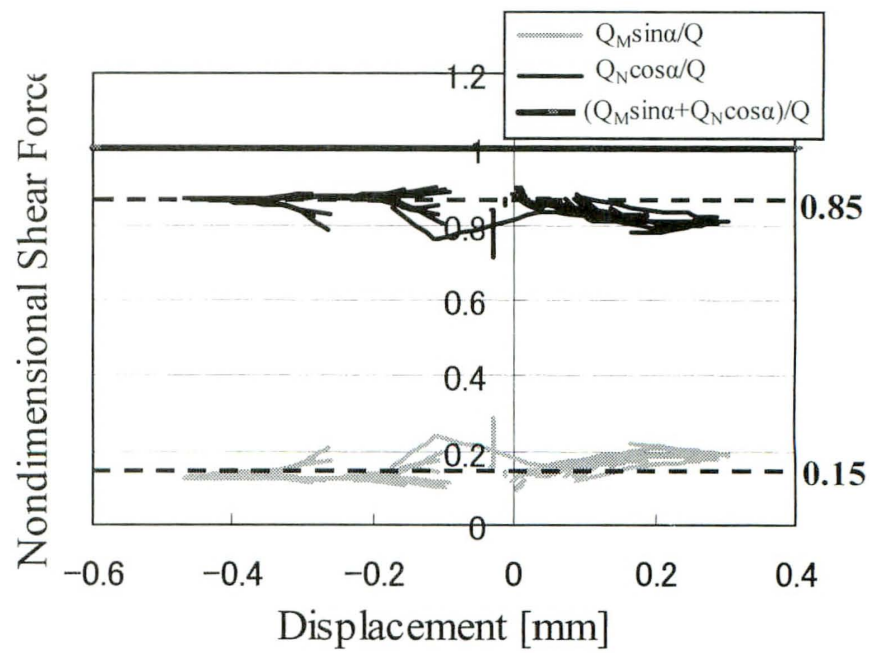

Fig.10 The Ratio of Flexural Force to Axial Force(C-0-45) 


\section{Concluding Remarks}

Following are concluded.

As for hysteretic characteristics;

1) In all the specimens, the asymmetry was observed in the hysteresis loop because the size of concrete cover was insufficient in tensile loading.

2) The pinching effect was so pronounced and less energy absorption was expected, because the crack development and opening was dominated, and the rebar did not show a plastic behavior up to the end of the repeated loading..

3) Shear stiffness of Group B with some distance were inferior to A, because deformability was improved by setting up some distance on the interface. On the other hand, that of Group $\mathrm{C}$ with the inclined angle were superior to A because a resistance by axial force was generated by rebar diagonally arranging.

As for shear transfer mechanism of rebar;

4) Shear transfer of dowel rebar could be explained by a cantilever model with linear moment distribution assumption.

5) In the specimens with the inclined angle, applied shear force was transferred as flexural force action and axial force action of rebar. In addition, the ratio of flexural force to axial force was 15 to 85 in C-0-45. On the other hand, the ratio in C-0-30,60 was 30 to 70 .

\section{References}

1) A. Shibata: Seismic analysis of structures, Morikita Publishing Co., p.49 (2003) (in Japanese) 